\title{
Efeito da polinização por abelhas e outros insetos na produção de sementes de cebola(1)
}

\author{
Sidia Witter(2) e Betina Blochtein ${ }^{(3)}$
}

\begin{abstract}
Resumo - A deficiência de polinização tem sido apontada como uma das causas da baixa produção de sementes na cultura da cebola. O objetivo deste trabalho foi avaliar a relação da presença de abelhas e outros insetos em flores de duas cultivares de cebola, Allium cepa L. (Alliaceae), com a produção de sementes. Foram registradas a diversidade e a frequiência de insetos nas flores de cebola e o efeito polinizador foi testado. O comportamento de Apis mellifera foi observado diretamente nas flores e a fidelidade verificada a partir do pólen nas corbículas. Representantes de Hymenoptera e Diptera foram os visitantes florais mais abundantes. Houve correlação entre a freqüência de $A$. mellifera com número de umbelas com flores, em ambas cultivares, e de outros insetos em Crioula Alto Vale. A produção de sementes com livre visitação de insetos apresentou acréscimo superior a $20 \%$ em relação às parcelas sem insetos e com visita de uma abelha. A. mellifera transportou mais de $70 \%$ de pólen de cebola. A presença de A. mellifera é indispensável para a produção comercial de sementes de cebola.
\end{abstract}

Termos para indexação: Allium cepa, Apis mellifera, polinizadores.

\section{Effect of pollination by bees and other insects on the production of onion seeds}

\begin{abstract}
Pollination's deficit has been pointed as one of the causes of the low onion seed production. The objective of this work was to evaluate the relationship of the presence of bees and other insects in flowers of two cultivars of onion, Allium cepa L. (Alliaceae), with seed production. The diversity and frequency of insects in flowers of onion was registered and their pollinizing effect was tested. The behavior of Apis mellifera was directly observed in the flowers and the fidelity was testified from the presence of pollen in the corbiculas. Representatives of Hymenoptera and Diptera were the most abundant flower visitors. There was a correlation between frequency of A. mellifera and the number of umbels with flowers in both cultivars and of other insects in Crioula Alto Vale. The production of seeds with free insect visitation had an increase of more than $20 \%$ in relation to others without insects and with the visitation of one bee. A. mellifera transported more than $70 \%$ of onion pollen. The presence of A. mellifera is indispensable for the commercial production of onion seeds.
\end{abstract}

Index terms: Allium cepa, Apis mellifera, pollinators.

\section{Introdução}

Entre as espécies cultivadas da família Alliaceae, a cebola (Allium cepa L.) é a mais importante sob o ponto de vista de volume de consumo e de valor econômico (Castellane et al., 1990). No Brasil, a ce-

\footnotetext{
(1)Aceito para publicação em 29 de setembro de 2003.

(2)Universidade da Região da Campanha, Dep. de Ciências Biológicas, Av. Tupy Silveira, 2099, CEP 96400-110 Bagé, RS. E-mail: sidiawitter@yahoo.com.br

(3) Pontifícia Universidade Católica do Rio Grande do Sul, Faculdade de Biociências, Av. Ipiranga 6681, CEP 90619-900 Porto Alegre, RS. E-mail: bblochtein@pucrs.br
}

bola é a terceira hortícola em importância econômica e, em razão da mão-de-obra requerida, também tem grande relevância social (Instituto de Planejamento e Economia Agrícola de Santa Catarina, 1990). Seu cultivo para produção de sementes, na fronteira sudoeste do Rio Grande do Sul, começou há mais de 30 anos. Essa região é considerada privilegiada para o cultivo da cebola por condições de solo e clima propícios, principalmente em relação ao fotoperíodo, temperatura e umidade (Sampaio et al., 1998). O Rio Grande do Sul é responsável por $90 \%$ da produção nacional e, deste porcentual, $40 \%$ a $50 \%$ são produzidos nesta região (Sampaio et al., 1998). De acordo com Sampaio et al. (1998), a produtividade média 
(350 kg/ha) de sementes de cebola na região alcança índice superior ao de Minas Gerais (289,68 kg/ha) (Lorenzon \& Martinho, 1994). Apesar disso, a produtividade média de sementes de cebola no Brasil é menor que nos EUA, ou seja, $986 \mathrm{~kg} / \mathrm{ha}$ a $1.358 \mathrm{~kg} / \mathrm{ha}$ (Campbell et al., 1968; Parker, 1982).

A baixa produção de sementes de cebola é atribuída às condições meteorológicas (Currah, 1981), às práticas culturais (Bohart et al., 1970; Parker, 1982; Castellane et al., 1990), ao efeito de doenças de controle difícil (Currah, 1981; Castellane et al., 1990), a limitações na receptividade do estigma e viabilidade do pólen (Nye et al., 1971) e a deficiências na polinização (Bohart et al., 1970; Waters, 1972; Castellane et al., 1990; Sampaio et al., 1998).

Em A. cepa pode ocorrer a autopolinização, entretanto predomina a polinização cruzada (McGregor, 1976; Currah \& Ockendon, 1978). A ação dos insetos é indispensável na polinização de flores de cebola e produção de sementes em escala comercial (Bohart et al., 1970; Benedek \& Gaal, 1972), para a qual A. mellifera tem sido extensivamente utilizada (Bohart et al., 1970; Williams \& Free, 1974; Ewies \& El-Sahhar, 1977). Waters (1972) relatou que a produtividade média de sementes de cebola, de $1.570 \mathrm{~kg} / \mathrm{ha}$, aumentou para $2.242 \mathrm{~kg} / \mathrm{ha}$, em 1971, com o uso intensivo de abelhas e sem a presença de floradas competitivas. Segundo Bohart et al. (1970), a redução de polinizadores gera problemas na produção de sementes de cebola. Parker (1982) verificou que poucos insetos estão presentes em lavouras comerciais de sementes de cebola em conseqüência do uso indiscriminado de pesticidas e da destruição de locais para a nidificação. Além disso, Bohart et al. (1970) e Williams \& Free (1974) registraram o desvio dos polinizadores para cultivos com floradas concomitantes.

São conhecidas 276 espécies de insetos que visitam flores de cebola e destes, Hymenoptera e Diptera são os mais importantes polinizadores (Bohart et al., 1970; Williams \& Free, 1974; Ewies \& El-Sahhar, 1977; Woyke, 1981). Da ordem Hymenoptera, A. mellifera destaca-se como a mais importante espécie polinizadora (Bohart et al., 1970; Woyke, 1981).

O objetivo deste trabalho foi avaliar a relação entre a presença de insetos em flores de duas cultivares de cebola e a produção de sementes.

\section{Material e Métodos}

O estudo foi realizado em lavoura para produção comercial de sementes de cebola, da empresa Hortec Sementes, com uma área de 2,5 ha, em Candiota, na região sudoeste do Estado do Rio Grande do Sul. O clima da região é mesotérmico, subtropical, com temperatura média anual de $17,6^{\circ} \mathrm{C}$ e umidade relativa do ar entre $75 \%$ e $85 \%$.

Os trabalhos no campo foram desenvolvidos entre outubro e dezembro de 1999 e 2000, utilizando duas cultivares de polinização aberta, Crioula Alto Vale (EPAGRI 362) em 1999 e Bola Precoce (EMPASC 352) em 2000.

$\mathrm{Na}$ lavoura as mudas de cebola foram dispostas linearmente com espaçamento de $15 \mathrm{~cm}$ entre as plantas e $80 \mathrm{~cm}$ entre as linhas. Foi utilizado calcário, fertilizante (NPK) e fungicida e no controle de "trips" foram realizadas duas aplicações de Decis 25 CE em Bola Precoce e três em Crioula Alto Vale.

A vegetação ao redor da lavoura era formada por campos mistos (Macedo, 1984), a uma distância inferior a $1.000 \mathrm{~m}$, com cultivos de couve (Brassica spp.), abóbora (Cucurbita spp.), cenoura (Daucus carota Linnaeus), salsa (Petrocelinum sativum Hoffmann) e coentro, (Coriandrum sativum Linnaeus), com floração paralela à cebola.

Os insetos associados às flores de cebola foram coletados, duas vezes por semana, em três períodos de uma hora, às $10 \mathrm{~h}, 13 \mathrm{~h}$ e $16 \mathrm{~h}$, durante o período de floração (1999 e 2000), em ambas cultivares. Esses insetos foram coletados com rede entomológica e acondicionados em frascos de vidro com papel umedecido com acetato de etila. Posteriormente, em laboratório, os espécimes foram fixados com alfinetes entomológicos, catalogados e etiquetados conforme a data e o horário da coleta. A frequiência dos insetos em cebola foi registrada, ao longo das linhas dos cultivos, percorrendo-se $420 \mathrm{~m}$ de distância $(\mathrm{n}=138$ plantas), durante a floração, em três períodos de trinta minutos (9h30min-10h, 12h30min-13h e 15h30min-16h), uma vez por semana em Crioula Alto Vale e uma vez a cada quatro dias em Bola Precoce. O registro das abelhas foi realizado por família ou táxon inferior enquanto o restante dos insetos por ordem.

O monitoramento da floração foi realizado a partir de 100 plantas marcadas com fita de plástico, em quatro pontos distribuídos nas extremidades e oito no interior da lavoura. Durante o período de floração (Crioula Alto Vale: 27/10/1999 a 22/12/1999; Bola Precoce: 10/11/2000 a 28/12/2000), contou-se nas plantas marcadas o número de umbelas com flores abertas. Os registros de Crioula Alto Vale foram semanais e de Bola Precoce a cada quatro dias. 
No teste da eficiência dos insetos na polinização de flores de cebola, comparou-se a produção de sementes em quatro experimentos: na ausência de insetos, com a visita de uma abelha (A. mellifera), com livre visitação de insetos e, finalmente, com polinização manual. Para cada experimento, oito umbelas de quatro plantas da cultivar Crioula Alto Vale foram marcadas aleatoriamente com fita de plástico colorida. No teste com visita de uma abelha foram utilizadas todas as umbelas das plantas marcadas $(\mathrm{n}=15)$.

O cálculo do porcentual de sementes estabelecidas foi efetuado segundo Jones \& Emsweller (1934):

Estabelecimento da semente $=(100 \overline{\mathrm{x}} \mathrm{s} / \mathrm{u}) /(\overline{\mathrm{x}} \mathrm{u} / \mathrm{u})(6 \mathrm{rs} / \mathrm{f})$ em que, $\overline{\mathrm{X}} \mathrm{s} / \mathrm{u}$ é a média do número de sementes produzidas por umbela; $\bar{x}$ f/u é a média do número de flores por umbela e rs/f são os rudimentos seminais por flor.

$\mathrm{Na}$ avaliação das plantas sem a visita de insetos, quatro plantas foram protegidas individualmente com uma armação de metal $(0,60 \times 0,60 \times 1,60 \mathrm{~m})$, coberta com tecido de malha fina, impedindo o acesso dos insetos às flores.

No teste com visita de uma abelha, utilizou-se A. mellifera, o inseto mais freqüente nas flores de cebola. As quatro plantas foram protegidas com armação de metal revestida com tecido de malha fina. Quando constatou-se que as umbelas marcadas apresentavam mais de $25 \%$ de flores abertas (24/11/99), a armação de cada planta foi retirada, permitindo a visita de uma abelha por umbela. Logo após, as plantas foram cobertas novamente até o final da floração (22/12/99).

Na polinização manual, quatro plantas foram marcadas e, adicionalmente à livre visitação de insetos, as flores das umbelas foram polinizadas manualmente. Para isso, realizou-se contatos tocando-se estas flores com outras de umbelas recém-colhidas em outros pontos da lavoura. Este procedimento foi repetido diariamente, desde a presença de flores com estilo de $4 \mathrm{~mm}$ de comprimento, até a senescência de todas as flores da umbela.

No experimento com livre visitação de insetos, avaliou-se a biologia reprodutiva das duas cultivares em condições naturais. Ao final da floração, as umbelas foram colhidas, anotado o número total de flores não fecundadas e cápsulas. As últimas, foram classificadas segundo o número de sementes produzidas ( 1 a 6 ).

Observações individuais e diretas de A. mellifera $(\mathrm{n}=160)$ foram realizadas nas flores de Crioula Alto Vale, em 12/11 e 22/11/99, entre 10h30min e 14h30min, anotando-se contato com anteras e estigmas, recursos coletados (néctar e pólen), tempo de visita por umbela, número de flores visitadas por umbela e região percorrida da umbela. A fidelidade de $A$. mellifera foi avaliada por meio da análise do pólen armazenado nas corbículas. As abelhas com pólen nas corbículas foram coletadas diretamente das flo- res de cebola, usando-se rede entomológica, em três períodos diários e acondicionadas em frascos individuais. A carga polínica de uma das corbículas foi isolada e preparada com gelatina glicerinada/fucsina (Louveaux et al., 1978). Posteriormente, foram examinados 1.000 grãos de pólen, sob microscópio, calculando-se o porcentual do pólen de cebola.

A freqüência de abelhas e de outros insetos em relação ao número de umbelas com flores abertas foi analisada utilizando testes de correlação (Pearson) e de significância (teste t de Student). As diferenças do número de visitas de abelhas às flores de cebola, em três horários, foram comparadas utilizando-se o teste estatístico Wilcoxon Signed Ranks. A relação entre o número de flores visitadas e o tempo de visita despendido pelas abelhas nas umbelas foi comparada aplicando-se a análise de regressão.

\section{Resultados e Discussão}

Himenópteros e dípteros destacaram-se pela maior abundância nas duas cultivares de $A$. cepa (Tabela 1), o que também foi verificado por Bohart et al. (1970). Hymenoptera representou 67\% (Crioula Alto Vale) e $86 \%$ (Bola Precoce) do total de insetos capturados destacando-se $A$. mellifera com $57,9 \%$ (Crioula Alto Vale) e 77,7\% (Bola Precoce). Bohart et al. (1970) e Woyke (1981) também apontaram A. mellifera como o principal polinizador de cebola.

Além de A. mellifera, outros himenópteros foram representativos nas flores de cebola, totalizando 9,1\% em Crioula Alto Vale e 8,7\% em Bola Precoce. Sugere-se que esses insetos devem ser mantidos por meio de medidas conservacionistas, especialmente Mourella caerulea e Bombus spp. Essas espécies nidificam no solo e a proteção de seus ninhos, aliada à manutenção de parcelas de vegetação natural, poderia representar importante contribuição para a polinização de plantas cultivadas e silvestres. De acordo com Kearns \& Inouye (1997), a redução das abelhas pode trazer sérias implicações em ecossistemas naturais e agrícolas.

Comparando-se o padrão sazonal da floração de cebola com a atividade dos visitantes florais, observou-se que a frequência de A. mellifera e de outros insetos cresceu com o aumento do número de umbelas com flores abertas (Figura 1). Na cultivar Crioula Alto Vale, a correlação entre a freqüência de A. mellifera e o número de umbelas com flores foi 
alta $(r=0,92 ; \mathrm{p}<0,01)$, assim como a dos outros insetos $(r=0,90 ; p<0,01)$. Na cultivar Bola Precoce a correlação entre a freqüência de $A$. mellifera e o número de umbelas com flores abertas foi considerada média $(\mathrm{r}=0,66 ; \mathrm{p}<0,05)$. Quanto à presença de outros insetos e o número de umbelas com flores abertas na cultivar Bola Precoce, não observou-se correlação $(\mathrm{r}=0,51 ; \mathrm{p}>0,05)$.

As flores de cebola foram atrativas para A. mellifera e a presença significativa desta espécie limitou-se a 14 dias em Crioula Alto Vale, e a 8 dias em Bola Precoce. Nos dois casos, a maior frequiência de abelhas coincidiu com a maior disponibilidade de umbelas com flores abertas. Segundo Ewies \& El-
Sahhar (1977), a atratividade de A. cepa para A. mellifera é variável e está relacionada a diferenças de cultivares, clima, floradas competitivas e qualidade do néctar.

Nos três horários observados, o número de visitas de A. mellifera às flores de cebola foi progressivamente maior desde o período matutino até as $16 \mathrm{~h}$, indicando diferença significativa da frequêencia nas cultivares Crioula Alto Vale ( $\mathrm{p}<0.01)$ e Bola Precoce $(\mathrm{p}<0,05)$. No período de plena floração, entre $9 \mathrm{~h} 30 \mathrm{~min}$ e $10 \mathrm{~h}$ existiam 5 a 10 abelhas e, entre $12 \mathrm{~h} 30 \mathrm{~min}$ e $13 \mathrm{~h}$, 11 e 16 abelhas por $10 \mathrm{~m}$ de canteiro nas cultivares Crioula Alto Vale e Bola Precoce, respectivamente. No intervalo entre $15 \mathrm{~h} 30 \mathrm{~min}$ e $16 \mathrm{~h}$ houve aumento

Tabela 1. Insetos coletados em flores de cebola das cultivares Crioula Alto Vale (1999) e Bola Precoce (2000).

\begin{tabular}{|c|c|c|c|c|}
\hline \multirow[t]{2}{*}{ Ordem } & \multirow[t]{2}{*}{ Família } & \multirow[t]{2}{*}{ Espécie } & \multicolumn{2}{|c|}{ Número de indivíduos } \\
\hline & & & Crioula Alto Vale & Bola Precoce \\
\hline \multirow[t]{31}{*}{ Hymenoptera } & \multirow[t]{9}{*}{ Apidae } & Apis mellifera Linnaeus 1758 & 2.410 & 2.990 \\
\hline & & Mourella caerulea (Friese, 1900) & 105 & 64 \\
\hline & & Bombus bellicosus Smith, 1879 & 12 & 5 \\
\hline & & Bombus (Fervidobombus) atratus Franklin, 1913 & 5 & 6 \\
\hline & & Xylocopa (Neoxylocopa) augusti Lepeletier, 1841 & 12 & 7 \\
\hline & & Xylocopa (Megaxylocopa) frontalis (Olivier, 1789) & 1 & 1 \\
\hline & & Xylocopa sp. A & 1 & 0 \\
\hline & & Xylocopa sp. B & 0 & 1 \\
\hline & & Xylocopa $\mathrm{sp.C}$ & 1 & 0 \\
\hline & \multirow[t]{13}{*}{ Halictidae } & Acamptopoeum cf. prinii (Holberg, 1884) & 4 & 6 \\
\hline & & Paroxistoglossa cf. brachycera Moure, 1969 & 2 & 0 \\
\hline & & Augochloropsis cleopatra (Schrottki, 1902) & 1 & 0 \\
\hline & & Augochloropsis sp. & 1 & 6 \\
\hline & & Augochloropsis spp. & 7 & 12 \\
\hline & & Augochloropsis sp. A & 2 & 1 \\
\hline & & Augochloropsis sp. B & 1 & 0 \\
\hline & & Dialictus (Chloralictus) $\mathrm{sp}$. & 14 & 0 \\
\hline & & Dialictus (Dialictus) spp. & 17 & 2 \\
\hline & & Augochlora (Oxystoglosella) semiramis (Schrottky, 1910) & 4 & 0 \\
\hline & & Pseudogapostemon (Pseudogapostemon) brasiliensis Cure, 1989 & $\begin{array}{l}4 \\
8\end{array}$ & 12 \\
\hline & & Augochlorella iopoecila (Moure, 1950) & 1 & 0 \\
\hline & & Thectochlora alaris (Vachal, 1904) & 0 & 1 \\
\hline & Andrenidae & Anthrenoides sp. & 1 & 0 \\
\hline & Megachilidae & & 4 & 0 \\
\hline & Formicidae & & 2 & 1 \\
\hline & Vespidae & & 156 & 191 \\
\hline & Pompilidae & & 12 & 13 \\
\hline & Tiphiidae & & 5 & 3 \\
\hline & Mutilidae & & 0 & 1 \\
\hline & Ichneumonidae & & 1 & 4 \\
\hline & Scoliidae & & 1 & 1 \\
\hline \multirow[t]{4}{*}{ Diptera } & \multirow[t]{2}{*}{ Syrphidae } & Palpada sp. & 97 & 148 \\
\hline & & Allograpta $\mathrm{sp.}$ & 37 & 20 \\
\hline & Bibionidae & & 793 & 69 \\
\hline & Outras & & 245 & 124 \\
\hline Coleoptera & & & 161 & 137 \\
\hline Hemiptera & & & 10 & 9 \\
\hline Lepidoptera & & & 19 & 9 \\
\hline Neuroptera & & & 8 & 4 \\
\hline Total de insetos & & & 4.161 & 3.848 \\
\hline
\end{tabular}


na atividade de A. mellifera, isto é, 13,33 (Crioula Alto Vale) e 19,6 (Bola Precoce) abelhas. Com base nestes dados, observou-se que o número de visitas de A. mellifera nas flores está relacionado com o horário do dia, o que também foi constatado por Carlson (1974). Woyke (1981), verificou 49 e 76 abelhas por $10 \mathrm{~m}$ de canteiro, entre $12 \mathrm{~h}$ e $14 \mathrm{~h}$, em duas cultivares em plena floração.

Em oito umbelas de cebola, com livre visita de insetos, $48 \%$ (Crioula Alto Vale) e 55,80\% (Bola Precoce) das flores desenvolveram cápsulas. $\mathrm{Na}$ mesma região, Sampaio et al. (1998) registraram a formação de $64 \%$ de cápsulas e atribuíram a perda à falta de polinização. É comum entre as angiospermas a produção de uma maior quantidade de flores e óvulos do que frutos e sementes maduros (Brendon \& Spencer, 2000). Determinadas espécies produzem mais de 1.000 flores para cada fruto maduro. Em outras, as flores podem desenvolver $50 \%$ ou mais frutos. Portanto, esta proporção pode variar entre populações, indivíduos de uma população e a cada ano (Stephenson, 1981).
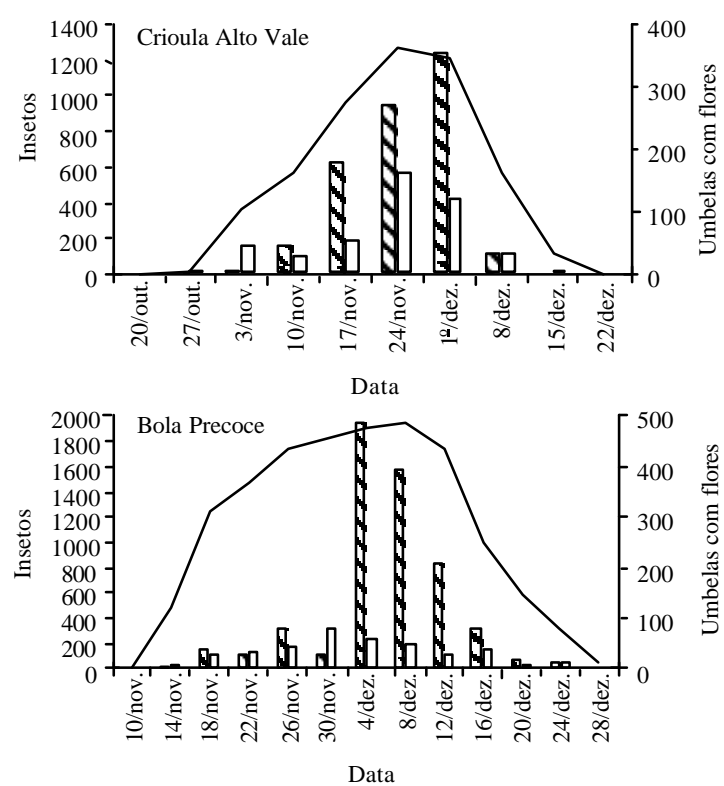

Figura 1. Freqüência de Apis mellifera ( $\mathbf{\$}$ ) e de outros insetos ( $\square$ ) em flores de Allium cepa, cultivares Crioula Alto Vale e Bola Precoce durante o período de floração e o total de umbelas com flores $(-)$.
O maior porcentual de sementes foi produzido em cápsulas com duas e cinco sementes e aquelas com três sementes foram mais freqüentes nas duas cultivares (Figura 2). Ewies \& El-Sahhar (1977) e Parker (1982) constataram médias entre 3,2 e 3,7 sementes por cápsula em $A$. cepa na presença de insetos. Cada ovário de $A$. cepa possui três lóculos, cada um contendo dois rudimentos seminais, podendo haver a formação máxima de seis sementes por cápsula (McGregor, 1976). Em contraposição, percebe-se que $42 \%$ e $28,5 \%$ das sementes em ambas cultivares foram produzidas em cápsulas com quatro, cinco, e seis sementes. Sampaio et al. (1998) registraram que $44 \%$ das sementes foram produzidas em cápsulas de quatro ou mais sementes.

A reduzida produção de sementes de cebola na região é decorrente das perdas evidenciadas nas médias de sementes/cápsula (Figura 2) e nos porcentuais de cápsulas/umbela (48,0\% e 55,8\%). Segundo Sampaio et al. (1998), a fecundação de flores poderia ser aumentada em mais que o dobro com maior eficiência no processo de polinização e com a interferência de variáveis relacionadas à quantidade e ao tipo de agentes polinizadores. As abelhas (A. mellifera) foram os insetos mais abundantes nas flores de cebola e como possuem características de efetivos polinizadores, a produtividade pode ser otimizada mediante manejo da espécie. De acordo com MacGregor (1976), os produtores de sementes de cebola dependem de $A$. mellifera como principal polinizador. Jones \& Emsweller (1934), Bohart et al. (1970) e Woyke (1981) também observaram que a polinização por insetos é indispensável para produção de sementes de cebola (Tabela 2).

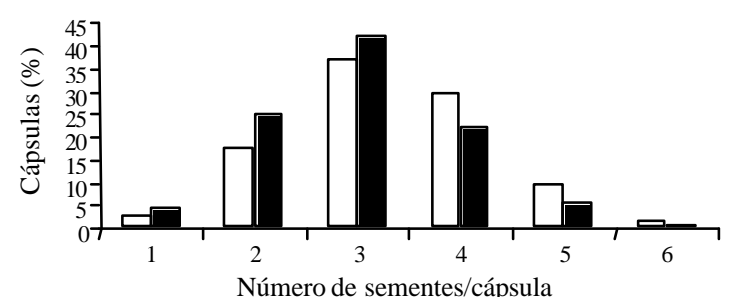

Figura 2. Número de sementes produzidas por cápsula de Allium cepa cultivar Crioula Alto Vale $(\square)$ e Bola Precoce () com livre visita de insetos. 
Nos experimentos realizados sem visitas de insetos, a produção de cápsulas e de sementes foi menor que nas parcelas com visitas de insetos e com o acréscimo de polinização manual (Tabela 2). Neste caso atribuiu-se a produção resultante à autopolinização (Bohart et al., 1970). Segundo Parker (1982), experimentos reforçam a hipótese de que a autopolinização resulta num alto porcentual de aborto de sementes.

A produção de cápsulas e sementes com a visita de uma abelha é comparável àquela sem insetos. Este tratamento indica a necessidade de maior pressão polinizadora. Esta hipótese é reforçada comparando-se os resultados obtidos na ausência de abelhas e com a visita de uma abelha com os de livre visita de insetos, em que houve um acréscimo na produção de sementes superior a 20\% (Tabela 2). Confirma-se assim a importância da ação polinizadora dos insetos para a produção de sementes de cebola em escala comercial, registrada também por Woyke (1981).

Semelhante porcentual de sementes estabelecidas na ausência de insetos $(1,5 \%)$ foi constatado por Ewies \& El-Sahhar (1977). Na presença de insetos, o porcentual de sementes estabelecidas $(23,29 \%)$ aproximou-se dos resultados $(29,6 \%)$ verificados por Jones \& Emsweller (1934). Ewies \& El-Sahhar (1977) registraram resultados superiores $(61,8 \%)$ utilizando colônias de A. mellifera. Com base nesses resultados, estima-se que a produtividade de sementes de A. cepa possa aumentar mais do que o dobro com manejo adequado de $A$. mellifera.

$\mathrm{O}$ número médio de sementes produzidas por umbela com polinização manual ( $\bar{x}=314,62$; $\mathrm{s}=152,64)$ foi inferior ao obtido nas parcelas visitadas por insetos $(\bar{x}=827,25 ; \mathrm{s}=333,62)$ (Tabela 2$)$.
Este resultado pode ser atribuído ao método utilizado, em que o número de grãos de pólen que alcançam o estigma não pode ser controlado. Lorenzon \& Almeida (1997) também verificaram que a polinização manual não foi eficiente em aumentar o número de grãos de pólen germinados nos estigmas de $A$. cepa. Na polinização manual, perdas na produção são atribuídas a quantidades insuficientes de pólen (Kwak \& Jennersten, 1991) e ao excesso de grãos no estigma (Young \& Young, 1992).

Ao visitarem as flores, as abelhas tocavam as anteras e os estigmas. As operárias coletavam ativamente o néctar enquanto o pólen era obtido indiretamente durante o deslocamento entre as flores. Em virtude da disposição das anteras, o pólen adere facilmente aos pêlos do corpo das abelhas durante suas visitas às flores para coletar néctar (Ewies \& ElSahhar, 1977). Em alguns casos, durante a coleta de néctar, as abelhas despendem algum tempo na região inferior da umbela, limpando o pólen do corpo, descarregando-o. A grande quantidade de pólen sobrecarrega-as e estimula-as a livrarem-se do excedente, permitindo que prossigam na coleta de néctar. Esse comportamento também foi observado por Williams \& Free (1974).

Cada indivíduo de A. mellifera permaneceu numa umbela entre 3 e 151 segundos $(\bar{x}=23,19 ; \mathrm{s}=22,35)$ e visitou de 2 a $30(\bar{x}=6,67 ; s=5,03)$ flores. Das abelhas observadas, $76,9 \%$ permaneceram menos de 30 segundos em uma umbela. Benedek (1977) constatou que $57 \%$ das abelhas permaneceram menos de 30 segundos por umbela. Williams \& Free (1974) reportaram visitas de 43,9 e 38,3 segundos enquanto Currah \& Ockendon (1984), 18 segundos por umbela. Observou-se correlação entre o número

Tabela 2. Produção média de flores, cápsulas e sementes por umbela de cebola das cultivares Crioula Alto Vale (CAV) (1999) e Bola Precoce (BP) (2000) em resposta aos tratamentos.

\begin{tabular}{|c|c|c|c|c|c|}
\hline \multirow[t]{2}{*}{ Produção por umbela } & \multirow{2}{*}{$\begin{array}{c}\text { Ausência de insetos } \\
\text { CAV }\end{array}$} & \multirow{2}{*}{$\begin{array}{c}\text { Livre visitação de uma abelha } \\
\text { CAV }\end{array}$} & \multicolumn{2}{|c|}{ Livre visitacão de insetos } & \multirow{2}{*}{$\begin{array}{c}\text { Polinização manual } \\
\text { CAV }\end{array}$} \\
\hline & & & CAV & $\mathrm{BP}$ & \\
\hline Flores $\left(\mathrm{n}^{\circ}\right)$ & 472,62 & 627,66 & 591,75 & 641,87 & 363,75 \\
\hline Cápsulas $\left(\mathrm{n}^{\mathrm{o}}\right)$ & 18,62 & 19,46 & 283,75 & 358,20 & 119,37 \\
\hline Cápsulas (\%) & 3,90 & 3,10 & 47,90 & 55,80 & 32,80 \\
\hline Sementes $\left(\mathrm{n}^{\mathrm{0}}\right)$ & 42,62 & 40,13 & 827,25 & 945,12 & 314,62 \\
\hline Estabelecimento de sementes (\%) & 1.50 & 1,00 & 23,29 & 24.54 & 14,40 \\
\hline
\end{tabular}


de flores visitadas e o tempo de visita das abelhas por umbela (Figura 3), em concordância com Benedek (1977). Williams \& Free (1974) observaram que uma operária visitou em média 7,2 flores por umbela para coletar néctar e tocou 37,6 flores, polinizando provavelmente mais flores do que aquelas exploradas para obtenção de néctar. Na cultivar Crioula Alto Vale, observou-se que uma abelha visitou em média 6,67 flores por umbela. Considerando a estimativa (Williams \& Free, 1974) de que uma abelha toca cinco vezes mais flores do que visita na coleta de néctar, estima-se que cada abelha tocou em média 33,35 flores por umbela. Benedek (1977) afirma que $20 \%$ a $30 \%$ das flores de uma umbela estão com o estigma receptivo simultaneamente. Considerandose que uma umbela tem em média 591,75 flores, propõe-se que 4,5 visitas diárias são necessárias para uma satisfatória produção de sementes numa umbela durante o tempo total de floração. Benedek (1977) sugere que 5 a 8 visitas diárias em uma umbela durante o período total de floração são requeridas para uma produção de sementes satisfatória.

Segundo Benedek \& Gaal (1972), o fato de A. mellifera despender pouco tempo por inflorescência indica que essa espécie pode ser mais eficiente que outros insetos na polinização cruzada. Currah \& Ockendon (1984) verificaram que A. mellifera visita poucas flores por umbela e utiliza umbelas independentemente do tamanho, ao contrário de dípteros que visitam muitas flores por umbela e preferem umbelas grandes, promovendo maior índice de autocruzamentos. Para Currah \& Ockendon (1978), a quantidade de autocruzamentos em cebola pode variar e altos índices em plantas de polinização aberta devem induzir perdas na produtividade.

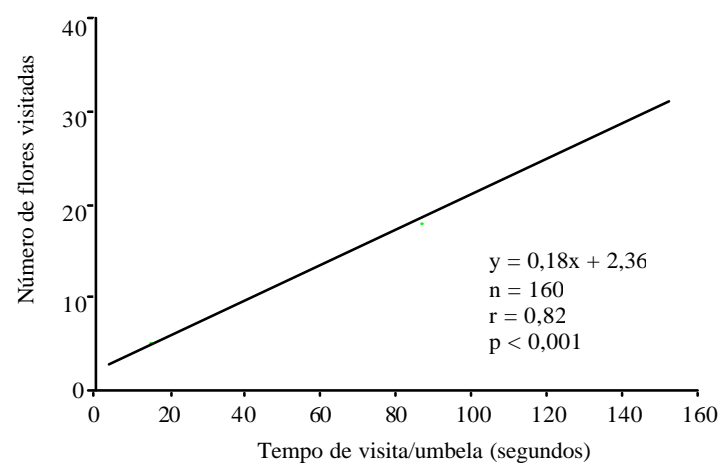

Figura 3. Número de flores de cebola visitadas por Apis mellifera em relação ao tempo de visita despendido por umbela.
As umbelas, de forma esférica, apresentam flores em vários estágios de desenvolvimento distribuídas irregularmente. Entretanto, 85\% das abelhas visitaram com maior freqüência a região mediana. Consequentemente, mais flores desta região da inflorescência foram polinizadas. A maioria das abelhas, $57,5 \%$, tocou duas ou as três regiões da umbela, enquanto $42,5 \%$ permaneceram na mesma região da umbela em que pousaram, contrariando os dados obtidos por Benedek (1977).

A análise das cargas polínicas de $A$. mellifera revelou que o porcentual médio de pólen de $A$. серa cultivar Crioula Alto Vale e Bola Precoce foi de respectivamente $75,86 \%$ e $95,67 \%$. Os índices de pólen de cebola verificados neste trabalho são surpreendentes quando comparados aos $6 \%$ a $8 \%$ obtidos por Nye et al. (1971) nos EUA. Analisando-se qualitativamente as cargas polínicas ao longo do dia, verificou-se que os porcentuais de pólen em Crioula Alto Vale variaram mais que em Bola Precoce (Tabela 3). Na cultivar Crioula Alto Vale registrou-se maior influência de floradas competitivas; em dois casos (10 e 18/11/1999) 100\% do pólen transportado era de cenoura, de lavoura próxima. A cebola é pouco atrativa como recurso de pólen, comparativamente a outros cultivos, a exemplo de Daucus carota (Free, 1993), Brassica (Williams \& Free, 1974) e Citrus (Ewies \& El-Sahhar, 1977). Com base nestes conhecimentos, sugere-se o planejamento das lavouras a fim de evitar plantas competitivas ou manejar A. mellifera intensivamente prevendo-se também os cultivos que florescem simultaneamente com a cebola.

Tabela 3. Porcentual de pólen de cebola nas cultivares Crioula Alto Vale (1999) e Bola Precoce (2000) transportado por Apis mellifera ${ }^{(1)}$.

\begin{tabular}{|c|c|c|c|}
\hline Dias & $10 \mathrm{~h} 30 \mathrm{~min}$ & $12 \mathrm{~h} 30 \mathrm{~min}$ & $15 \mathrm{~h} 30 \mathrm{~min}$ \\
\hline & \multicolumn{3}{|c|}{ Crioula Alto Vale } \\
\hline $10 / 11$ & - & 0,00 & 98,29 \\
\hline $18 / 11$ & - & 98,29 & - \\
\hline $24 / 11$ & 24,23 & 99,57 & 96,79 \\
\hline $2 / 12$ & 98,96 & 95,45 & 99,12 \\
\hline $9 / 12$ & 99.70 & 99.09 & 97.73 \\
\hline Média \pm desvio-padrão & $74.29 \pm 43.36$ & $65.4 \pm 50.67$ & $98.38 \pm 0.69$ \\
\hline & \multicolumn{3}{|c|}{ Bola Precoce } \\
\hline $16 / 11$ & - & 96,59 & 81,22 \\
\hline $27 / 11$ & 99,27 & - & 94,94 \\
\hline $6 / 12$ & 97,19 & 97,99 & 98,39 \\
\hline $15 / 12$ & 99,51 & 95,19 & - \\
\hline $22 / 12$ & 93,15 & - & 99,00 \\
\hline Média \pm desvio-padrão & $96,61 \pm 3,21$ & $96,59 \pm 1,4$ & $93,38 \pm 8,30$ \\
\hline
\end{tabular}

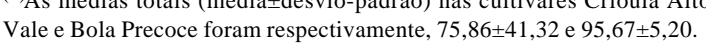




\section{Conclusão}

Apis mellifera é o inseto polinizador indicado para o manejo na produção comercial de sementes de cebola.

\section{Referências}

BENEDEK, P. Behaviour of honeybees (Apis mellifera L.) in relation to the pollination of onion (Allium cepa $\mathrm{L}$.) inflorescences. Zeitschrift für Angewandte Entomologie, Berlin, v. 82, p. 414-420, 1977.

BENEDEK, P.; GAAL, E. The effect of insect pollination on the seed onion, with observations on the behaviour of honeybees on the crop. Journal of Apicultural Research, Cardiff, v. 11, n. 3, p. 175-180, Jan. 1972.

BOHART, G. E.; NYE, W. P.; HAWTHORN, L. R. Onion pollination as affected by different levels of pollinator activity. Bulletin of the Utah Agriculture Experiment Station, Logan, v. 482, p. 1-60, Oct. 1970.

BRENDON, M. H. L.; SPENSER, C. H. B. A comparative analysis of pollen limitation in flowering plants. Biological Journal of the Linnean Society, London, v. 69, p. $503-$ 520 , July 2000.

CAMPBELL, W. F.; COTNER, S. D.; POLLOCK, B. M Preliminary analysis of the onion seed (Allium cepa, L.) production problem, 1966 growing season. HortScience, Alexandria, v. 3, n. 1, p. 40-41, 1968.

CARLSON, E. C. Onions varieties, honeybees visitations, and seed yield. California Agriculture, Oaklana, v. 28, n. 9, p. 16-18, Sept. 1974.

CASTELLANE, P. D.; NICOLOSI, W. M.; HASEGAWA, M. Produção de sementes de hortaliças. Jaboticabal: FCAV/Funep, 1990. 261 p.

CURRAH, L. Onion flowering and seed production. Scientific Horticulture, Kent, v. 32, p. 26-46, 1981.

CURRAH, L.; OCKENDON, D. J. Pollination activity by blowflies and honeybees on onions in breeders cages. Annals of Applied Biology, Wellesbourne, v. 105, p. $167-$ 176, Feb. 1984.

CURRAH, L.; OCKENDON, D. J. Protandry and the sequence of flower opening in the onion (Allium cepa L.). New Phytologist, Cambridge, Inglaterra, v. 81, p. 419428, Jan. 1978.

EWIES, M.; EL-SAHHAR, K. F. Observations on the behavior honeybees on onion and their effects on the seed yield. Journal of Apicultural Research, Cardiff, v. 16, n. 4, p. 194-196, Feb. 1977.

FREE, J. B. Insect pollination of crops. London: Academic, 1993. 684 p.

INSTITUTO DE PLANEJAMENTO E ECONOMIA AGRÍCOLA DE SANTA CATARINA (Florianópolis, Santa Catarina). Síntese anual da agricultura de Santa Catarina. Florianópolis, 1990. 369 p.

JONES, H. A.; EMSWELLER, S. L. The use of flies as onion pollinators. Journal of the American Society for Horticultural Science, McMinnville, v. 31, p. 160-164, 1934.

KEARNS, C. A.; INOUYE, D. W. Pollinators, flowering plants, and conservation biology. Bioscience, Washington, v. 47, n. 5, p. 297-307, May 1997.

KWAK, M. M.; JENNERSTEN, O. Bumblebee visitation and seedset in Melampyrum pratense and Viscariavulgaris: heterospecific pollen limitation. Oecologia, Berlin, v. 86, p. 99-104, Oct. 1991.

LORENZON, M. C. A.; ALMEIDA, E. C. Viabilidade e germinação do pólen de linhagens parentais de cebola híbrida. Pesquisa Agropecuária Brasileira, Brasília, v. 32, n. 4, p. 345-349, abr. 1997.

LORENZON, M. C. A.; MARTINHO, M. R. Comportamento das abelhas africanizadas (Apis mellifera L.) quando aprisionadas em ensaios de polinização. Pesquisa Agropecuária Brasileira, Brasília, v. 29, n. 11, p. 16851690, nov. 1994.

LOUVEAUX, J.; MAURIZIO, A.; VORWHL, G. Methods of melissopalynology. Bee World, Cardiff, v. 59, n. 4, p. 139-157, 1978.

MACEDO, W. Levantamento de reconhecimento dos solos do município de Bagé, RS. Brasília: EmbrapaUepae de Bagé, 1984. 69 p.

McGREGOR, S. E. Insect pollination of cultivated crop plants. Washington: United States Department of Agriculture, 1976. $411 \mathrm{p}$.

NYE, W. P.; WALLER, G. D.; WATERS, N. Factors affecting pollination of onions in Idaho during 1969 Journal of the American Society for Horticultural Science, McMinnville, v. 96, n. 3, p. 330-332, 1971.

PARKER, F. D. Efficiency of bees in pollinating onion flowers. Journal of the Kansas Entomological Society, Lawrence, v. 55, n. 1, p. 171-176, May 1982. 
SAMPAIO, T. G.; SAMPAIO, N. V.; SOARES, P. F. Estudo de componentes do rendimento na produção de sementes de cebola (Allium cepa L.). Revista Científica Rural, Bagé, v. 3, n. 1, p. 1-7, 1998.

STEPHENSON, A. G. Flower and fruit abortion: proximate causes and ultimate functions. Annual Review of Ecology and Systematics, Palo Alto, v. 12, p. 253-279, 1981

WATERS, N. D. Honey bee activity in blooming onion field in Idaho. American Bee Journal, Hamilton, v. 112, n. 6, p. 218-219, June 1972.
WILLIAMS, I. H.; FREE, J. B. The pollination of onion (Allium cepa L.) to produce hybrid seed. Journal of Applied Ecology, Oxford, v. 11, p. 409-417, Jan. 1974.

WOYKE, W. H. Some aspects of the role of the honeybees in onion seed production in Poland. Acta Horticulturae, Leuven, v. 111, p. 91-97, 1981.

YOUNG, H. J.; YOUNG, T. P. Alternative outcomes of natural and experimental high pollen loads. Ecology, Houston, v. 73, n. 2, p. 639-647, June 1992. 